\title{
Gastric Cancer Challenges in Young Adults: Genetic and Socioeconomic Features in Different Brazilian Country Regions
}

\author{
Maria Lucia Hirata Katayama ${ }^{1}$, Rosimeire Aparecida Roela ${ }^{1}$, Simone Maistro ${ }^{1}$, Marina \\ Candido Visontai Cormedi ${ }^{1}$, Edia Filomena Di Tullio Lopes ${ }^{2}$, Rodrigo Santa Cruz Guindalini ${ }^{1,3}$ \\ and Maria Aparecida Azevedo Koike Folgueira*1 \\ ${ }^{1}$ Instituto do Cancer do Estado de Sao Paulo, Departamento de Radiologia e Oncologia, Universidade de Sao Paulo, Brazil \\ ${ }^{2}$ Instituto do Cancer do Estado de Sao Paulo, Registro Hospitalar de Cancer, Universidade de Sao Paulo, Brazil \\ ${ }^{3}$ CLION, CAM Group, Brazil
}

Received: March 05, 2018; Published: March 19, 2018

*Corresponding author: Maria Aparecida Azevedo Koike Folgueira, Associate Professor, Instituto do Câncer do Estado de São Paulo Hospital das Clínicas da Faculdade de Medicina da Universidade de São Paulo Departamento de Radiologia e Oncologia Av. Dr. Arnaldo, 251, 8º andar, sala 69 01246-000, São Paulo, SP, Brasil, Tel: 5511 38933032; Email: maria.folgueira@fm.usp.br

\section{Abstract}

Gastric cancer in young adults is a challenging situation. In Brazil, recent data indicates that most of them are diagnosed with advanced disease and that CDH1 germline mutations are not frequently detected. It is high time to characterize the spectrum and frequency of germline mutations in gastric cancer young patients and to improve health care to high risk individuals.

Keywords: Cancer Gastric; Young adults

\section{Opinion}

More than $70 \%$ of gastric cancer cases occur in developing countries, with the highest incidence rates observed in East Asia, Latin America, Central and Eastern Europe [1]. Although the incidence of stomach cancer has declined over the years 1975 to 2005 in several European countries, as well as in some Asian countries [2], in Brazil, the estimated age-standardized rate of new cases per 100,000 persons per year is still considered moderate/ high (9.2) as compared with the USA (3.9), France (4.7), Argentina (6.7), Spain (6.7), Italy (8.2), China (22.7) and Japan (29.9) [3]. In Brazil, there are estimates that 13,540 new cases in men and 7,750 in women, will occur in the years 2018-2019, indicating that gastric cancer assumes the fourth and the sixth places in cancer incidence among men and women, respectively [4]. In young people, gastric cancer incidence is low, representing about 3.5\% of the total cases, in individuals aged 15-39 years [2]. Nonetheless, at least two studies have shown an increased or flattened incidence in young patients from the USA and Korea [5,6], in contrast with decreasing trends in all ages incidence.
In most countries, the 5-year survival rate for gastric cancer has not changed and remained between $25-30 \%$ in the $1995-99$ to 2005-09 periods, but not in Brazil, where unfortunately, there was a trend towards a gradual reduction in 5-year overall survival along the last quinquenniums [7]. In Brazil, there was a trend towards increased lethality rates between 2005 and 2010, especially among the younger population $[8,9]$. Brazil is a subcontinental country, comprehending 26 states, grouped in five geographic regions (North, Northeast, Midwest, Southeast and South), that is home to 207, 7 million people [10]. Among these regions, contrasting socioeconomic and environmental characteristics, as well as disparate nutrition habits and cultural customs are observed. The North and Northeast regions present lower socioeconomic indices than other regions in the country, depicted by a monthly per capita household income of US\$238 in the Northeast region compared with US\$ 421 in the Southeast region [11].

Estimates of adjusted incidence rate of gastric neoplasm per 100,000 inhabitants in Brazil reveal differences among the 
Brazilian regions and considering males, it is the second most frequent in the North $(15.19 / 100,000)$ and Northeast (8.84), fourth in the South (14.98) and Midwest (15.4), fifth in the Southeast (9.11). In females, gastric cancer is the fifth more frequent in the North $(6.46 / 100,000)$, South (5.95) and Midwest (6.55), sixth in the Northeast (5.66) and seventh in the Southeast (3.71) (excluding non-melanoma skin cancers) [4]. The time series of mortality rates for stomach cancer in Brazil, according to regions, for males and females, between 1980 and 2009, show a decreasing trend in the South, Southeast, and Midwest regions, for both sexes, in contrast with a relative stability in the North region and increased rates in the Northeast region, over the period, also for both sexes [12]. Similar projections indicate that both the North and Northeast regions will face increments in gastric cancer mortality rates in the coming years, that may be partly due to difficulties in access to health care. Changes in mortality rates however, may also reflect improvements in cancer diagnosis, as well as in death registry data [13].

Two recently published manuscripts dealt with gastric cancer in young adults in our country in patients from the North or Northeast regions of Brazil $[14,15]$. In one study, patients from four families that fulfilled clinical criteria for Hereditary Diffuse Gastric Cancer syndrome were submitted to genetic screening analysis at Pará state (North region). In two families, patients developed cancer at ages before 40 years. In one of these families, gastric cancer affected a father and a son and CDH1 mutation was attributed to a Japanese ethnic background, as this mutation was previously described in Japan. In another family, two brothers were involved and CDH1 mutation was probably associated with their European descent from Portugal [14]. In another study, 41 individuals with ages below 46 years constituted a younger group of gastric cancer patients followed at Fortaleza, capital of Ceará state (Northeast region). Among these patients, 61\% were males, $44 \%$ and $56 \%$ reported chronic tobacco smoking and alcohol consumption, respectively, and 7\% reported family history of gastric cancer. Regarding clinic- pathological characteristics, most patients reported abdominal pain (90\%), weight loss (76\%), vomit (66\%), anemia (54\%). Most patients were diagnosed with diffuse gastric cancer (71\%) and advanced disease, clinical stages III/IV (73.2\%), including 49\% with metastatic disease (49\%) [15].

We have recently analyzed clinical characteristics of young gastric cancer patients treated at Instituto do Câncer do Estado de São Paulo (ICESP) [16], a reference cancer hospital from São Paulo city. São Paulo (SP), located in the Southeast region of the country, is the most-populous Brazilian state with estimated 45,15 million inhabitants in 2017, corresponding to $21.7 \%$ of the Brazilian population [17] São Paulo (capital of SP state), crossed by the Tropic of Capricorn, is the largest city in Brazil and its metropolitan area has more than 20 million people [18]. Instituto do Câncer do Estado de São Paulo, ICESP, integrates the Brazilian public health network (SUS, Sistema Único de Saúde) and is the largest reference cancer hospital in Latin America. Our estimates in a previous study, was that $48 \%$ of our patients were born in São Paulo State and $52 \%$ were born in other regions of the country (mainly in the Northeast region) [19]. From May 1st, 2008 to April 30th, 2014, 2,374 patients with stomach neoplasm were registered at ICESP, among whom, $148(6.23 \%)$ were young adults (ages 20 to 39 years), mostly of them diagnosed with carcinomas $(86.5 \%)$, followed by sarcomas (6.7\%), lymphomas (5.4\%) and carcinoid tumors (1.3\%).

Among 128 gastric carcinomas diagnosed in young adults, most were classified as signet ring cell adenocarcinoma or diffuse type carcinoma (58.6\%), adenocarcinoma NOS (22.6\%) and tubular adenocarcinoma (7.0\%). In addition, among 126 gastric carcinoma patients staged by the TNM system, $0.8 \%, 6.4 \%, 4.0 \%, 11.9 \%$ and $77.0 \%$ were classified as clinical stages 0 , I, II, III, IV, respectively. In a subgroup of 71 patients with ages until 40 years the median survival was 15 months and overall survival was similar to older adults [20,21]. Thirty nine young patients (below 40 years) were prospectively included from 2013 to 2015, for CDH1 gene sequencing, however none of them were found to be mutation carriers, even though eight already reported family history of gastric and/or breast cancer [22,23]. In summary, there are some challenges that may be figured out in order to provide a better assistance to young adults with gastric cancer. In Brazil, most young gastric cancer patients are diagnosed with advanced disease. In this age group, $\mathrm{CDH} 1$ mutation is not frequently detected, even though it may be found in patients with affected first degree relatives. This data indicates that gastric cancer deserves a better approach in order to characterize the spectrum and frequency of germline mutations and to improve health care to high risk individuals.

\section{Acknowledgement}

This work was supported by a grant from NAP-Biobanco/ USP. MCVC receveid a initiation reseach grant from PIBIC/CNPq (Conselho Nacional de Desenvolvimento Científico e Tecnológico). MAAKF received a research productivity grant from CNPq.

\section{References}

1. Park JY, von Karsa L, Herrero R (2014) Prevention strategies for gastric cancer: a global perspective. Clin Endosc 47(6): 478-489.

2. Ferlay J, Steliarova-Foucher E, Lortet-Tieulent J, Rosso S, Coebergh JW, et al. (2013) Cancer incidence and mortality patterns in Europe: estimates for 40 countries in 2012. Eur J Cancer 49(6): 1374-403.

3. Ferlay J, Soerjomataram I, Ervik M, Dikshit R, Eser S, et al. (2013) F GLOBOCAN v1.0, Cancer Incidence and Mortality Worldwide: IARC Cancer Base No. 11 Lyon France: International Agency for Research on Cancer, France.

4. Brasil, Ministério da Saúde, Instituto do Câncer-INCA (2018) Accessed.

5. Anderson WF, Camargo MC, Fraumeni JF Jr, Correa P, Rosenberg PS, et al. (2010) Age-specific trends in incidence of noncardia gastric cancer in US adults. JAMA 303(17): 1723-1728.

6. Song HN, Go SI, Lee WS, Kim Y, Choi HJ, et al. (2016) Population-Based Regional Cancer Incidence in Korea: Comparison between Urban and Rural Areas 2015. Cancer Res Treat 48(2): 789-797.

7. Allemani C, Weir HK, Carreira H, Harewood R, Spika, et al. (2015) Global surveillance of cancer survival 1995-2009: analysis of individual data for 25,676,887 patients from 279 population-based registries in 67 countries (CONCORD-2). Lancet 385(9972):977-1010.

8. Amorim CA, Moreira JP, Rial L, Carneiro AJ, Fogaça HS, et al. (2014) Ecological study of gastric cancer in Brazil: geographic and time trend analysis. World J Gastroenterol 20(17): 5036-5044. 
9. Cormedi MCV and Folgueira MAAK (2017) Letter to the Editor. Rev Med (São Paulo) 96(2): 134-135.

10. Instituto Brasileiro de Geografia e Estatística (IBGE) Database.

11. Instituto Brasileiro de Geografia e Estatística (IBGE) Database.

12. Guimarães RM, Muzi CD (2012) Trend of mortality rates for gastric cancer in Brazil and regions in the period of 30 years (1980-2009). Arq Gastroenterol 49(3): 184-188.

13. de Souza Giusti AC, de Oliveira Salvador PT, Dos Santos J, Meira KC, Camacho AR, et al. (2016) Trends and predictions for gastric cancer mortality in Brazil. World J Gastroenterol 22(28): 6527-6538.

14. Moreira-Nunes CA, Barros MBL, do Nascimento Borges B, Montenegro RC, Lamarão LM, et al. (2014) Genetic screening analysis of patients with hereditary diffuse gastric cancer from northern and northeastern Brazil. Hered Cancer Clin Pract 12(1): 18-26.

15. Braga-Neto MB, Carneiro JG, Barbosa AMC, Silva IS, Maia DC, et al. (2018) Clinical charactristics of distal gastric câncer in Young adults from northeastern Brazil. BMC Cancer 18: 131.

16. Instituto do Câncer do Estado de São Paulo Octavio Frias de Oliveira (ICESP).

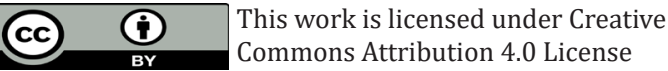

Submission Link: https://biomedres.us/submit-manuscript.php
17. (2018) https://g1.globo.com/sao-paulo/noticia/populacao-de-saopaulo-ultrapassa-12-milhoes-de- habitantes-diz-ibge.ghtml.

18. Instituto Brasileiro de Geografia e Estatística (IBGE) Database.

19. Maistro S, Teixeira N, Encinas G, Katayama ML, Niewiadonski VD, et al (2016) Germline mutations in BRCA1 and BRCA2 in epithelial ovarian cancer patients in Brazil. BMC Cancer 16(1): 934-942.

20. Cormedi MCV, Lopes EFT, Roela RA, Maistro S, Folgueira MAAK (2018) Clinical stage and histological type of the most common carcinomas diagnosed in young adults in a reference cancer hospital.

21. Cormedi MCV, Katayama MLH, Guindalini RSC, Faraj SF, Folgueira MAAK (2018) Survival and prognosis of young adults with gastric cancer.

22. Guindalini RSC, Pasini FS, Gôuvea ACRC, Branas PA, Cormedi MCV, et al. (2015) J Clin Oncol 33e12535) USA.

23. Guindalini RSC (2016) Identificação de variantes germinativas no gene E-caderina/CDH1 e de fatores ambientais de risco em pacientes jovens portadores de câncer gástrico. Faculdade de Medicina da Universidade de São Paul SP Brasil.

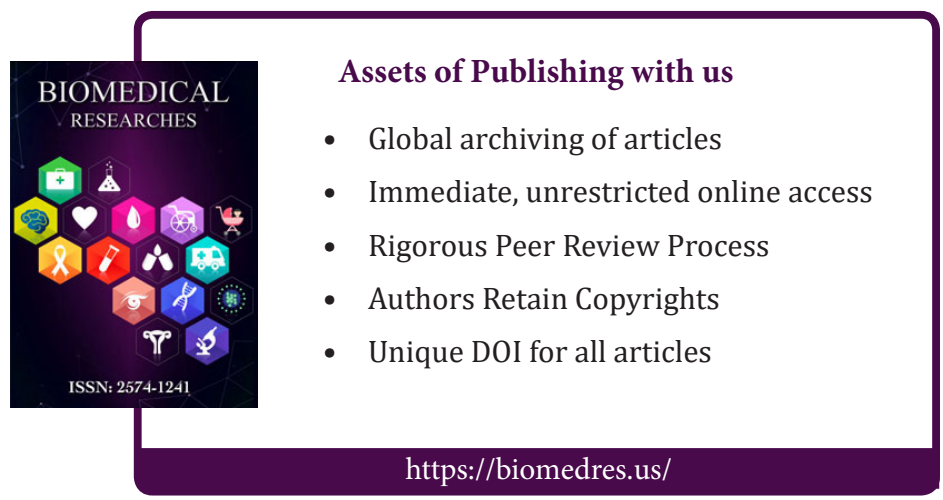

